\title{
Development of Mohanamai Network for Road Traffic Injury Management Lesson Learned of Thailand
}

\author{
Boonruang Khaonuan ${ }^{1}$ \\ ${ }^{I}$ Department of Public Health Faculty of Health and Sports Science, Thaksin University, Thailand \\ "Corresponding author. Email: boonruang@tsu.ac.th
}

\begin{abstract}
Mohanamai is a public health professional who works in primary care settings. The purpose of this project was to develop the capability of a Mohanamai network for the management of road traffic injuries in the local community. The research and development approach was used to maximize the potential of the Mohanamai network for dealing with traffic accidents. The target group consists of leaders of 100 Mohanamai who are interested in conducting academic research on road traffic injury management. According to the study's results, Mohanamai is a group of primary health care personnel who are crucial in organizing community-based road safety management. All participants improved their ability to manage road traffic injury management, gained confidence, and gained the ability to work and drive road traffic injury management in their communities.
\end{abstract}

Keywords: Mohanamai network, road traffic injury, capacity building

\section{INTRODUCTION}

Primary care offered prime services most directly to the general public .It was a major mechanism and strategy for the development of the national public health system to ensure public access to necessary health care fairly and continuously, and contribute to efficient public health care together with favorable health outcomes without too high expenditure .International empirical evidence indicated that primary care facilitated accessibility to necessary health care and promote health care equality for people .Strength of primary care was positively related to health conditions of people in the country, and primary care took a significant role in improving people's health and accessibility to health care, especially for poor and underprivileged people in the society [1], [2], [3].

Currently, under the National Health Security System, the majority of primary care was supervised by the government sector, whereby $94.75 \%$ of primary care units were managed by Ministry of Public Health, followed by the private sector, while the public sector, ranging from local administrative organizations, public organizations apart from Ministry of Public Health, universities, Ministry of Defense, and Contracting Unit for Primary Care, were altogether in the same character . The management pattern of Contracting Unit for Primary Care was provided through a primary care network, with its management center reporting primarily to the hospital. At the moment, the development of primary care network management in the form of District Health (DHS) is evident due to the Ministry of Public Health's supporting policy in collaboration with several agencies, including the National Health Security Office, the Thai Health Promotion Foundation, and the Office of Community Based Health Care Research and Development. In B.E. 2556, the Ministry of Public Health designated the District Health System (DHS) policy as a critical policy for the development of the primary care network ]1 .[The Primary Care Unit or Sub-District Health Promoting Hospital or community health center were service facilities which closely provided comprehensive health care for individuals, families, and communities, including health promotion, prevention of illness, diagnosis for coping with health-threatening problems, medical treatment, and rehabilitation, as well as being connected with a variety of public health care for purpose of transfer of responsibilities .Moreover, it was connected with other relevant services systems .Such public health care did not feature academic and technological complexity, but its complexity was in the field of 
humanities and social [2], [3]. Sub-District Health Promoting Hospital aimed to provide services in response to people's demands, whereby people could access to the services, and health manpower possessed appropriate skills within affordable costs .Therefore, Sub-District Health Promoting Hospital needed to have sufficient skillful manpower [4].

Road traffic accidents, the leading cause of injury mortality and the tenth leading cause of death globally, now account for an unexpectedly substantial proportion of the global burden of illness. Each year, road accidents kill an estimated 1.2 million people and injure up to 50 million more. Thailand has road safety difficulties. According to a $2012 \mathrm{WHO}$ assessment, the nation has the highest rate of road traffic fatalities in South-East Asia, with 36.2 deaths per 100,000 inhabitants per year. The national action plan Decade for Action on Road Safety (2011-2020) intends to decrease road traffic fatalities to fewer than 10 per 100,000 people per year by 2020 , in accordance with Sustainable Development Goal 3.6, which calls for half worldwide road traffic fatalities and injuries by 2020. In Thailand, however, achieving this aim looks challenging due to the complexity of the issues at hand, which include individual, social, and environmental aspects [4], [5]. Thus, it is extremely necessary to develop existing systems and build up a new mechanism to deal with the subsequent problems. This study aimed to conduct a capacity building of the Mohanamai network for road traffic injury management in the local community.

\section{METHOD}

This study applied the research and development process to developing potential of Mohanamai network for dealing with road accidents .The target group includes leaders of 100 person of Mohanamai in nationwide who were interested in developing academic works in the area of road traffic injury management for mobilizing safety sub-district. The researcher made comparisons regarding road traffic injury management. The information meeting, knowledge exchange, community forum, community-based activities, information retrieval, conclusion, and lessons learned have all been used to put the plan into action .The data were collected were collected through community forum, focus group discussion, after action review and dialogue .The study lasted for 16 months from Janauary 2019 until April 2020 with qualitative data has been collected. The reliability of the collected were tested by triangulation method by comparing findings of phenomenon from place and perspective such as data triangulation, multiple investigator triangulation, review triangulation, and method triangulation. The data were analyzed using content analysis.

\section{RESULTS}

According to the findings, Mohanamai is a group of primary public health workers who play a critical role in the development of the community health system, including communicable disease control and prevention, comprehensive immunization, maternal and child care, home visit, environmental hygiene management, primary health care, and primary medical care, etc .with spirits of Mohanamai who is accessible, comprehensible, and ready to serve general public .Mohanamai or public health officials had been recognized as these were the health professionals widely available in every area that understood and got to know the community. They were trusted by the community and took a major role in driving mechanism of Thailand's health system .They were regarded as the main workforce of Ministry of Public Health for promoting health, preventing and controlling diseases .If Mohanamai could be developed to be enough knowledgeable for responding to the world situation and diseases, it would enable health promotion to be extensive and achieve most effectiveness.

The entire group of Mohanamai nationwide under the name of "Mohanamai Network "aims to form a group of people with ideology to have synergy in managing health risk factors in the community. The said network gains support from Thai Health Promotion Foundation (Thai Health) and Ministry of Public Health for campaigns, public relations, and community forums for purpose of mitigating health risk factors, namely, accident, alcoholic and beverage. All participants learned about road traffic injury management by using Five tools approach" for mobilizing road safety in the " .community

In this regard, information retrieval and knowledge management are the research instruments used to solve problems at the community level, to generate new body of knowledge, particularly in the areas of health promotion, disease prevention and control, and determinants of health protection, as well as to integrate other dimensions such as society, economics, politics, and the environment by leveraging Mohanamai's familiarity with the community. The Mohanamai network project is based on experiential and interactive learning. The establishment of information exchange forums at the provincial and municipal levels not only facilitates mutual learning, but also allows for the connection of other networks for the aim of resolving community health problems until health risk factors are eliminated, such as accident, and alcoholic beverage, become decreased, resulting in various community prototypes for mitigation of health risk factors all over Thailand. It seemed like building intellectual capital that helped all participants feel more confident, competencies, gain power for working and drive road traffic injury management. 


\section{DISCUSSIONS}

The Cabinet established a vision for developing and advancing Thailand in order to achieve stability, prosperity, and sustainability, and endorsed Thailand's reform of health services, health promotion systems, and determinants of health protection in order to strengthen and improve them, particularly at the local level. The 2030 Agenda for Sustainable Development highlights the importance of road safety in guaranteeing healthy lives, promoting well-being, and developing inclusive, safe, resilient, and sustainable cities. The United Nations General Assembly's official declaration of the Decade of Action for Road Safety 2011-2020 in March 2010 aims to save millions of lives by strengthening road safety management capacity; improving the safety of road infrastructure; further developing vehicle safety; improving road user behavior; and improving post-crash response. The Decade of Action, directed by the Global Plan, establishes a framework for policy, practice, and advocacy aimed at assisting nations in reaching the Sustainable Development Goal of sustainable development [6], [7].

The findings of this study indicate that Mohanamai is a group of primary health care providers who play a critical role in mobilizing community-based road safety management. In this context, information retrieval and knowledge management are the research instruments utilized to solve road accident problems at the local level, by generating new body of knowledge and establishing a framework for problem resolution. The establishment of information sharing forums enables other networks to interact for the goal of mutual learning in order to strengthen the management of road traffic injury concerns in communities .It is likely that this network will be able to achieve sustainability in managing road traffic injury in the local communities .It is essential for the networking approach to seek a flexible type of organization which features a flat structure and maintains independence as it is able to respond to complicated problems, changes, and high competition [8] .Since Mohanamai network originated from the connection of a group of people with "public mind "to work together, it is likely that this Network will be able to achieve sustainability in managing risk factors in the community .It was suggested having mechanism of supporting knowledge exchange among multi-professional networks, motivating the activity implementation, developing academic works from routine to research, and supporting management process for enhancing intellectual and social power [9], [10].

\section{ACKNOWLEDGMENT}

Author would like to thank the Thai Health Promotion Foundation (Thai Health) for granted budget this study.

\section{REFERENCES}

[1] National Reform Counsil .Proposal for Thailand's reform of health system .Report .The Secretariat of the House of Representative .Bangkok .2015.

[2] National Reform Counsil .Proposal for Thailand's reform of health service system .Report .The Secretariat of the House of Representative .Bangkok 2015.

[3] Anderson P, Pulich M .Managerial competencies necessary in today's dynamic health care environment Health Care Manag; 21:1-11.2002.

[4] McCaffery .Strengthening human resources management : knowledge, skills and leadership .Capacity project knowledge sharin g .2009.

[5] Mahon A, Young .R .Health care managers as a critical component of the health care workforce .In :Dubois CA, McKee M, Nolte E, editors .Human resources for health in Europe .England :Open University Press, McGrawHill .Education, 140-54 .2006. Wibulpolprasert S) .Eds .( Thailand Health Profile 2008-2010, WVO Office of printing Mill, Bangkok; 2011.

[6] Casio WF .Managing human resource .New York: MacGraw-Hill Book; 1995.

[7] Hudak RP, Brooke PP Jr, Finstuen K .Identifying management competencies for health care executives : review of a series of Delphi studies .J Health Adm Educ 2000; 18 :213-43; discussion 244-9.

[8] Rawson GK .Characteristics and educational needs of senior health service managers in Australia .J Health Adm Educ 1988; 6 :39-51.

[9] Khaonuan B. (Ed). Mohanamai moving "Pracharat" for reduce road traffic injury of Thailand. Yuttharin, Nonthaburi. 2017.

[10] Attaphumi K and Khaonuan B (Ed). Mohanamai network power for road traffic injury of Thailand. Yuttharin, Nonthaburi. 2020. 